\title{
A Cyber-Icebreaker For An Effective Virtual Group?
}

\author{
Tony Clear \\ Computing Systems \& Technology \\ Auckland University of Technology \\ Auckland \\ New Zealand \\ Tony.clear@aut.ac.uk
}

\author{
Mats Daniels \\ Dept of Computing Systems \\ Uppsala University \\ Uppsala \\ Sweden \\ Matsd@docs.uu.se
}

\begin{abstract}
This paper reports selected results from the most recent of a series of international collaborative trials between students at Auckland University of Technology and Uppsala University. The trials require students to work together in virtual groups, comprising students from each institution, to perform a common task. The topic of this paper is how to form and sustain more effective virtual groups. In this trial a cyber-icebreaker task has been introduced and its contribution to group effectiveness is explored. Some conclusions are drawn pinpointing the strengths and weaknesses of this trial design, and some insights into effective design of electronic collaborative learning groups are gained.
\end{abstract}

\section{Introduction}

Teaching using electronic collaborative learning groups [1] is a complex area for research, and many aspects of effective teaching and learning in such environments are poorly understood. In this trial a prototype web-based groupware product $[2,3]$ was used to support teams of students from two different Universities to jointly perform a common task. The task required students, who had never met one another, to collaborate across different time zones, institutions and country boundaries. In this trial the design incorporated a cyber-icebreaker task to assist students to become acquainted with their collaborating partners. This intervention was intended to improve group effectiveness and the overall results of the trial.

\section{Description of the Trial}

The trial described here occurs as the most recent in a series of international collaborative trials [3,5] using a custom developed web-based groupware application based upon Lotus Notes $^{\mathrm{TM}}$ and Domino ${ }^{\mathrm{TM}}$. Motivations for the trials include the following:

- Authors interest in international collaboration

- Enhancing the student learning experience

- Developing cross cultural communication capabilities

- Transformation of the education process using IT and collaborative pedagogy

- Exploring issues related to groupware

In this trial two sections of students studying an Intelligent Business Systems course at Auckland University of Technology were matched with a larger section of Computer Science students studying Information Technology at Uppsala University. This involved some $40 \mathrm{NZ}$ and 80 Swedish students collaborating to complete a common task over a period of some six weeks. Because of the unbalanced numbers, and the desire to keep group size small, typically one Auckland subgroup would be matched with two Uppsala subgroups to create an overall group of some 12 students. The trial required students to rank three design proposals posted to a collaborative database by students from a prior trial, and work together to achieve a consensus on their rankings at overall group level.

The process consisted of a largely sequential series of steps supported by online forms and views in the collaborative application. Students were also free to use the collaborative software or use standard email to assist them in this process. The two tasks requiring students to cooperate to come to a decision were: 1 ) the process of selecting an overall group leader and 2) the process of determining a consensus on their rankings. The table below excerpted from the instructions given to students indicates some of the steps and timings involved in the collaboration. 


\begin{tabular}{|c|c|c|}
\hline Date & Two Classes & \\
\hline $\begin{array}{l}\text { Tuesday } \\
12 / 09 / 00\end{array}$ & $\begin{array}{l}12: 00-1: 00 \mathrm{pm} \\
6: 00-7: 00 \mathrm{pm}\end{array}$ & $\begin{array}{l}\text { Individually within your allocated group } \\
\text { enter: } \\
\text { - your introductory statement then } \\
\text { - your clues }\end{array}$ \\
\hline $\begin{array}{l}\text { Thursday } \\
14 / 09 / 00\end{array}$ & $\begin{array}{l}6: 40-7: 00 \mathrm{pm} \\
12: 40-1: 00 \mathrm{pm}\end{array}$ & $\begin{array}{l}\text { Enter your guesses about the } \\
\text { identities of your other group } \\
\text { members based upon their clues } \\
\text { Report week1y progress } \\
\text { (individually) }\end{array}$ \\
\hline $\begin{array}{l}\text { Tuesday } \\
19 / 09 / 00\end{array}$ & $\begin{array}{l}12: 40-1: 00 \mathrm{pm} \\
6: 40-7: 00 \mathrm{pm}\end{array}$ & $\begin{array}{l}\text { - Complete any further guesses about } \\
\text { the identities of your other group } \\
\text { members }\end{array}$ \\
\hline $\begin{array}{l}\text { Thursday } \\
21 / 09 / 00\end{array}$ & $\begin{array}{l}6: 45-7: 00 \mathrm{pm} \\
12: 45-1: 00 \mathrm{pm}\end{array}$ & $\begin{array}{l}\text { - View team members guesses for } \\
\text { your own statement and score them } \\
\text { - } \quad \text { Individually score the three design } \\
\text { proposals } \\
\text { - } \quad \text { Individually rank the proposals } \\
\text { - Select a leader for your group }\end{array}$ \\
\hline $\begin{array}{l}25 / 09 / 00 \\
06 / 10 / 00\end{array}$ & $\overline{N / A}$ & Mid Semester Break in New Zealand \\
\hline $\begin{array}{l}\text { Tuesday } \\
17 / 10 / 00\end{array}$ & $\begin{array}{l}12: 45-1: 00 \mathrm{pm} \\
6: 45-7: 00 \mathrm{pm}\end{array}$ & 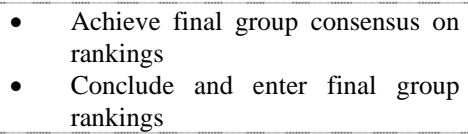 \\
\hline $\begin{array}{l}\text { Thursday } \\
19 / 10 / 00\end{array}$ & $\begin{array}{l}12: 30-1: 00 \mathrm{pm} \\
6: 30-7: 00 \mathrm{pm}\end{array}$ & - $\quad$ complete evaluation forms \\
\hline
\end{tabular}

Table 1. Key steps in the collaborative trial

Table 1 indicates the steps in the trial, the first key phase involving the icebreaker task, and the second involving the ranking task. The purpose of the icebreaker task was to help students get to know one another, prior to conducting the main task of the trial.

\subsection{The Cyber-icebreaker Task}

The steps in the icebreaker task involved students in: 1) posting an introductory statement, the contents of which were hidden in a virtual envelope, 2) posting clues to the content of their own envelopes - as phrases and images, 3) posting guesses for each of their team members based upon their clues, 4) scoring the guesses against your own clues, with these scores being ranked and an overall winner identified. The steps in this activity occurred serially, interdependently and asynchronously.

\section{Theoretical Frameworks}

Several theoretical frameworks inform this analysis, and they are briefly outlined here.

\subsection{Global Virtual Teams}

A global virtual team has been defined as a "temporary, culturally diverse, geographically dispersed, electronically communicating work group," and comprises teams "[4] where members may never have worked together before and may never expect to work together again as a group."[4] Internationally collaborating groups of students from different countries as reported in this trial, meet this definition. The study in [4] addressed the issues related to developing trust in virtual teams. Communication that rallies around the project and tasks appears to be necessary to maintain trust. Social communication that complements rather than substitutes for task communication may strengthen trust." [4]

The trust facilitating behaviours and actions are depicted in the table below.

\begin{tabular}{|l|l|}
\hline $\begin{array}{l}\text { Communication } \\
\text { Behaviors that } \\
\text { facilitated trust early in } \\
\text { a group's life }\end{array}$ & $\begin{array}{l}\text { Communication Behaviors that helped } \\
\text { maintain trust later in a group's life }\end{array}$ \\
\hline Social communication & Predictable communication \\
\hline $\begin{array}{l}\text { Communication of } \\
\text { enthusiasm }\end{array}$ & Substantial and timely responses \\
\hline $\begin{array}{l}\text { Member actions that } \\
\text { facilitated trust } \\
\text { early in a group's life }\end{array}$ & $\begin{array}{l}\text { Member actions that helped maintain } \\
\text { trust later in a group's life }\end{array}$ \\
\hline $\begin{array}{l}\text { Coping with technical } \\
\text { uncertainty }\end{array}$ & $\begin{array}{l}\text { Successful transition from social to } \\
\text { Procedural to task focus }\end{array}$ \\
\hline Individual initiative & Positive leadership \\
\hline & Phlegmatic response to crises \\
\hline
\end{tabular}

Table 2: Trust Facilitating Communication Behaviours and Member Actions (from [4])

The cyber-icebreaker task was seen as a mechanism to support several of these actions, cf. 4 below.

\subsection{Extended Adaptive Structuration Theory (EAST)}

This theoretical framework for group decision making in electronic tele-projects such as these cf. [3,5] proposes a form of input-process-output model. Output elements from the EAST model are used as constructs by which to determine and measure the effectiveness of group and trial outcomes.

\subsection{Activity Theory}

A number of factors are suggested in [6] to promote computer mediated communication (CMC) by helping users establish a "shared purpose". The rationale for this account is given by activity theory, which "situates behaviour within social contexts, via three levels of description: activity system, action, and operation. The activity system is the basic unit of analysis of group and individual behaviour, and comprises a subject (the group or individual) using tools (including writing and speech) to pursue an object (a global intention or purpose)".[6] It is argued that "From an activity theory standpoint shared purpose is critical to student usage of CMC in a number of ways."[6] For instance "lack of shared purpose would indicate the absence of any agreed activity system to organise and give meaning to joint action" and "shared perception of the task is at the core of any mechanism for construing the communications of others and anticipating their needs".[6]

\subsection{Factors Influencing the Success of CMC Environments in University Teaching}

A review of the use of CMC environments in university teaching [6] concluded that there were eight key factors to consider. These are depicted in the table below, and the 
ideal conditions proposed are contrasted with those actually in operation in this trial.

\begin{tabular}{|l|l|l|}
\hline Factor & Ideal Condition & Trial Condition \\
\hline 1. Size of group & Smaller is better e.g. 6 & $\begin{array}{l}\text { Approx 12 per group (4 } \\
\text { per subgroup) }\end{array}$ \\
\hline $\begin{array}{l}\text { 2. Knowledge of } \\
\text { other participants }\end{array}$ & $\begin{array}{l}\text { Better if participants } \\
\text { know each other }\end{array}$ & $\begin{array}{l}\text { Students unknown to } \\
\text { each other }\end{array}$ \\
\hline $\begin{array}{l}\text { 3. student } \\
\text { experience }\end{array}$ & $\begin{array}{l}\text { Better if students } \\
\text { experienced } \\
\text { communicators under } \\
\text { task conditions involved }\end{array}$ & $\begin{array}{l}\text { Uppsala students novices } \\
\text { Auckland students } \\
\text { novices to specific } \\
\text { database }\end{array}$ \\
\hline $\begin{array}{l}\text { 4. clarity about } \\
\text { task }\end{array}$ & $\begin{array}{l}\text { Better if students } \\
\text { understand how to go } \\
\text { about task, esp. if } \\
\text { understanding is shared }\end{array}$ & $\begin{array}{l}\text { Considerable confusion } \\
\text { about task evident } \\
\text { Need for some facilitator } \\
\text { intervention }\end{array}$ \\
\hline $\begin{array}{l}\text { 5. ownership of } \\
\text { task }\end{array}$ & $\begin{array}{l}\text { Better if students have } \\
\text { the chance to negotiate } \\
\text { what task is to involve }\end{array}$ & $\begin{array}{l}\text { Task predetermined, but } \\
\text { scope to negotiate } \\
\text { aspects of group process }\end{array}$ \\
\hline $\begin{array}{l}\text { 6. Need for } \\
\text { system }\end{array}$ & $\begin{array}{l}\text { Better if there is a clear } \\
\text { function for CMC which } \\
\text { cannot be served more } \\
\text { easily in another way }\end{array}$ & $\begin{array}{l}\text { Asynchronous } \\
\text { collaboration across time } \\
\text { zones and country } \\
\text { borders required to } \\
\text { complete task }\end{array}$ \\
\hline $\begin{array}{l}\text { 8. prior } \\
\text { experience of } \\
\text { CMC }\end{array}$ & $\begin{array}{l}\text { System configuration a } \\
\text { critical influence }\end{array}$ & $\begin{array}{l}\text { Prototype system } \\
\text { Group presentation } \\
\text { features[2] need } \\
\text { improvement }\end{array}$ \\
\hline important & $\begin{array}{l}\text { Uppsala students novices } \\
\text { to web based groupware } \\
\text { Auckland students prior } \\
\text { exposure to similar } \\
\text { groupware databases }\end{array}$ \\
\hline Tystem
\end{tabular}

Table 3: Factors Associated with Successful CMC Use in Higher Education - Contrasts with this Trial

As can be observed from the table above, there were many elements inherent in this trial that diverged from the ideal conditions.

\subsection{Activity Theory}

A further theory advanced in [6] suggests that the identified factors above promote CMC by helping users establish a "shared purpose". The rationale for this account is given by activity theory, which "situates behaviour within social contexts, via three levels of description: activity system, action, and operation. The activity system is the basic unit of analysis of group and individual behaviour, and comprises a subject (the group or individual) using tools (including writing and speech) to pursue an object (a global intention or purpose)".[6] It is argued that "From an activity theory standpoint shared purpose is critical to student usage of CMC in a number of ways."[6] For instance "lack of shared purpose would indicate the absence of any agreed activity system to organise and give meaning to joint action" and "shared perception of the task is at the core of any mechanism for construing the communications of others and anticipating their needs".[6]

\section{Analysis}

The role then of the cyber-icebreaker task was to improve the performance of the groups, by addressing several recommendations from the literature above. From 3.1 developing trust by addressing 1 ) the need for initial "social communication", and 2) the need to support a "successful transition from a social to procedural to task focus". From 3.2 by using specific constructs (e.g. task completions and consensus about decision outcomes) to measure outcome effectiveness in the analysis which follows below. From 3.3 as groups progress from "social to procedural to task focus", by attempting to develop a sense of "shared purpose" within the groups. From 3.4 by addressing the requirement (table 3 point 2) "Better if participants know each other".

The following analysis assesses the extent to which the cyber-icebreaker task has achieved its aims. This has resulted in the hypothesis that

H1: Successful performance on the cyber icebreaker task will enhance performance in the overall group ranking task.

The nature of the group/subgroup design generated some confusion amongst students, so the unit of analysis is problematic. At times results have been achieved at individual or subgroup level only, while the goal was for a consensus on rankings to be achieved at the overall group level. In the terms of 3.3 above three different "activity systems" can be seen in operation - at individual, subgroup and group level.

Overall group outcomes showed mixed degrees of success. Some groups achieved consensus only at the single subgroup level and thus their outcomes were scored at 33 percent whereas full group consensus was scored at 100 percent. Outcomes are tabulated below:

\begin{tabular}{|c|c|}
\hline Group Number & $\begin{array}{c}\text { Group Proposal Ranked } \\
\text { \% }\end{array}$ \\
\hline Group001 & 100 \\
\hline Group002 & 100 \\
\hline Group003 & 33 \\
\hline Group004 & 33 \\
\hline Group005 & 100 \\
\hline Group006 & 66 \\
\hline Group007 & 66 \\
\hline Group008 & 33 \\
\hline Group009 & 100 \\
\hline
\end{tabular}

Table 4: Group Level Performance on Proposal Ranking Task (Consensus about Decision Outcomes)

Factors such as student motivation, not covered in this paper, have also contributed to these variable success rates.

\subsection{Regression Analysis}

A series of single regression analyses have been run to indicate to what extent success in steps of the cyber-icebreaker task are correlated with success in achieving group rankings.

The constructs defined for the analysis represent a measure of the outcome of a key step in the trial. For the icebreaker task these are: Icebreaker statement postings; Icebreaker clue postings; Icebreaker guesses made; Icebreaker guesses scored (a measure of the percentage of guesses made actually scored for each group). For the ranking task, constructs are: Individual proposals scored; Individual proposals ranked; Group Leaders assigned (a measure of the 
degree to which groups have confirmed their group leaders); Group proposals ranked (a measure of the degree of completion and consensus about decision outcomes achieved by each group) - the dependent variable.

While the regression analysis indicated increasing degrees of correlation between success in subsequent steps in the icebreaker and ranking processes and the eventual outcome (Group Proposals Ranked), for most steps these correlations were not statistically significant. Probable causes for this initial lack of correlation are mixed degrees of completion of different stages, and the confusion between individual and group level entries. For instance in the group ranking task sequence the $\mathrm{R}^{2}$ value for individual proposals scored is higher (.366) than that for the subsequent individual proposals ranked (.194), although not statistically significant. In some cases students had been observed during the in-class sessions making joint entries on behalf of the subgroup, instead of individual entries as required by the task.

Two constructs however did correlate highly with successful overall performance. These came from single regression analyses between

1) Icebreaker guesses scored and Group proposals ranked resulting in a standardised beta coefficient of .767 at a .016 significance level

2) Group Leaders assigned and Group proposals ranked resulting in a standardised beta coefficient of .721 at a .028 significance level

The first of these correlations does lend support to our hypothesis:

H1: Successful performance on the cyber icebreaker task will enhance performance in the overall group ranking task.

This encouraging result does indicate that there is value in using a cyber-icebreaker task. The sheer number of student postings (approx 100\% completion rates on statement and clue postings, dropping to approx $25 \%$ for guesses) further supports this. Nonetheless the design of the icebreaker task had several flaws, which detracted from its value. Initially there was a flurry of postings from students and a real sense of excitement and engagement in the task, but the need to refer to statements and clues by codes rather than author names caused confusion at the guessing and scoring stages of the task. The response delays inherent in the asynchronous trial situation also seemed to cause a loss of momentum in the trial. A further weakness in the icebreaker design related to group size, and the sheer number of postings that needed to be made when entering guesses (in a group of 12 there would be 11 guesses to enter if all students had entered clues). This would need reconsidering in a future iteration, as the effort involved in the icebreaker task could swamp the main purpose of the trial.

Responses from student evaluations were mixed:

- $\quad$ "The initial enthusiasm generated by chatting up strangers went well. The icebreaker was a good ploy to get people talking about things other than the trial itself. The tone of conversations set by this relaxed and informal manner made it easy to work with the assigned group."

- $\quad$ "the Ice-Breaker Game, I believe was a fuzzy part of the whole assignment...was a mess, I didn't like it"

- What went well: "Maybe the cybericebreaking game, when we at last realized how it worked, but I don't think we got to know each other by doing that"

\section{Conclusion}

In the complex areas of international collaborative learning and web based groupware, the questions related to forging effective virtual groups are still being asked let alone answered. This trial with a cybericebreaker task has shown that an introductory exercise such as this, can improve the effectiveness of virtual groups. Determining how best to incorporate an icebreaker task in virtual group formation, and key elements of cyber-icebreaker design are questions for further study.

\section{Acknowledgments}

The cyber-icebreaker task was developed based upon a concept originally suggested by Elyssebeth Leigh from the University of Technology at Sydney.

\section{References}

[1] Fåhræus E, Chamberlain B., Bridgeman N., Fuller U., Rugelj J., (1999), Teaching with Electronic Collaborative Learning Groups in ITiCSE Working Group Reports, SIGCSE Bulletin, ACM Press New York pp 121 - 128

[2] Wheeler B., Dennis A., Press I., (1999), Groupware Comes To The Internet: Charting A New World, The DATABASE for Advances in Information Systems, 30;3\&4 Summer - Fall, pp. 8 -21

[3] Clear T., Daniels M., (2000), Using Groupware For International Collaborative Learning, Proceedings of the $30^{\text {th }}$ ASEE/IEEE Frontiers in Education Conference 2000, IEEE, October 18-21, Kansas, Missouri, pp. FIC $18-23$

[4] Jarvenpaa S., Leidner D., (1998), Communication and Trust in Global Virtual Teams, Journal of Computer Mediated Communication, 3; 4

[5] Clear, A., (1999), International Collaborative Learning - The Facilitation Process, ED-MEDIA Conference Proceedings - Addendum, June 19 -24, 1999, pp. 1759 1764, Seattle, Washington

[6] Tolmie A., Boyle J., (2000), Factors Influencing the success of computer mediated communication (CMC) environments in university teaching: a review and case study, Computers \& Education, 34, pp 119-140 